\title{
Construction of “Autonomous-Cooperative-Exploratory” Teaching Mode for Medical Students Based on Ability of Evidence-based Practice
}

\author{
Yexiang Yao \\ Public Health College, Qiqihar Medical University, Qiqihar Heilongjiang, 161006, China
}

Keywords: Ability of evidence-based practice, Medical students, Teaching mode construction, "Autonomous-cooperative-exploratory".

\begin{abstract}
The ability of evidence-based practice is a necessary requirement for medical talents in current medical field. The combination of "autonomous-cooperative-exploratory" teaching mode with the ability of evidence-based practice will largely avoid defects and shortcomings of traditional medical teaching mode, strongly drive stable development of medical education and contribute to promoting medical quality and deepening the reform of medical education. This paper analyzes the construction of "autonomous-cooperative-exploratory" teaching mode for medical students based on the ability of evidence-based practice and discusses the construction significance and method.
\end{abstract}

\section{Introduction}

Medical colleges and universities are the main bases to cultivate medical talents and they undertake the heavy responsibility of cultivating excellent medical talents. But traditional teaching mode has very large defects, such as low learning efficiency, listening to teachers carelessly, playing mobile phone in class and even cutting classes. These are very averse to medial education. Thus, it is imperative to explore new teaching modes, methods and ideas. The "autonomous-cooperativeexploratory" teaching mode for medical students based on the ability of evidence-based practice is one of the effective methods. It conforms to the era development and meets students' practical learning needs. Evidence-based medicine contains each knowledge point of clinic as well as abilities and thinking required for medical students. Besides, the implementation of “autonomous-cooperative-exploratory" teaching mode will largely improve learning status of medical students and enhance their ability of evidence-based practice and independent study awareness. In one word, the implementation of this mode will have great significance for medical colleges to cultivate high-quality medical talents.

\section{Construction significance of "autonomous-cooperative-exploratory" teaching mode for medical students based on the ability of evidence-based practice}

Poor independent learning ability and weak learning consciousness are ubiquitous phenomena in current classroom teaching. To be specific, the teacher teaches on the platform by himself/herself, and students listen to him/her occasionally. But most often, they do their own things, such as playing mobile phone, reading extracurricular books and chatting with other students. Besides, many students even cut classes or ask others to sign. They have poor learning initiative, without clear learning objective. Besides, their learning state is indolent. These abnormal phenomena are not just related to students themselves, but also have certain connection with traditional teaching method. The learning mode under such teaching mode presents the features of passiveness and individuality. Students' learning efficiency is low. This is also an prominent problem in the study of college students.

Medical colleges and universities undertake the heavy duty of cultivating medical talents. The learning quality of medical students directly influences medical education quality. The best guarantee for teaching quality is to teach students self-study method. Evidence-based medicine as a new teaching idea, mode and method plays an increasingly important role in medical education. 
Evidence-based medicine includes clinical knowledge and skills, clinical epidemiology, medical information acquisition and evaluation methodology, behavior ethics, critical thinking, medical statistics and so on. These contents are the key links for cultivating core abilities of medical students. Evidence-based practice starts from solving practical clinical problems and aims to overall cultivate medical students' abilities to discover problems, analyze problems, fully utilize developed internet resources to extensively gather information and apply medical information critically to solve problems. In addition, the "autonomous-cooperative-exploratory" teaching mode for medical students based on the ability of evidence-based practice changes the traditional situation where the teacher is centered and students mechanically receive knowledge. It takes evidence-based practice as the carrier, guides students to turn to independent study from passive learning, highlights cooperation and exploration process in the learning process and cultivates students' innovation and practice ability. Besides, it can offer new theoretical reference for medical teaching method reform. The change of teaching mode can promote the change of students' leaning mode. Meanwhile, through evidence-based practice, students closely connect the knowledge of various subjects with diseases through autonomous, cooperative and exploratory learning mode, achieve knowledge integration from theory to practice and complete the ability span from basis to clinic. Evidence-based practice has unique function in the aspect of cultivating clinical thinking ability of medical students, knowledge integration and utilization. Besides, it has important practical value for deepening teaching reform and improving medical teaching quality.

\section{Construction of "autonomous-cooperative-exploratory" teaching mode for medical students based on the ability of evidence-based practice}

\subsection{Basic concept, teaching method and strategy of "autonomous-cooperative-exploratory" teaching mode}

\subsubsection{To change teaching concept and thought, and cultivate a new learning mode}

Under the general background of new course education reform, traditional teaching concept of exam-oriented education and traditional teaching mode cannot adapt to era development and meet students' practical learning needs. Especially for education and teaching of medical colleges and universities, it is required to improve current situation of medical education, change teaching concept, actively construct "autonomous-cooperative-exploratory" teaching mode for medical students based on the ability of evidence-based practice, guide students to take active part in teaching activities, facilitate student-teacher cooperation and encourage medical students for innovation research and practice so as to establish medical knowledge hierarchy suitable for medical students. Simply speaking, the "autonomous-cooperative-exploratory" teaching mode for medical students based on the ability of evidence-based practice mainly emphasizes teaching-learning interaction between the teacher and students and exploration process. In the exploration and research, such mode creates independent learning atmosphere, mobilizes students' learning initiative, and encourages students to cooperate with each other, innovate and give full play to their subjective initiative for independently inquiry.

\subsubsection{Basic teaching method and teaching strategy of "autonomous-cooperative-exploratory" teaching mode}

(1) To integrate medical teaching materials again and flexibly apply medical teaching materials

The teaching of any subject cannot be separated from teaching materials and textbook knowledge support. It is also the case for medical education. The contents of teaching materials are roughly the whole process of classroom teaching; the teacher must carry out teaching activity design according to the specified teaching materials. But this does not mean to completely copy and paste the knowledge of teaching materials, but it is required to screen and re-organize the knowledge. So, medical teachers should correctly treat the contents of teaching materials, integrate and design again the textbooks and 
read various aspects involved in medical teaching materials, construct the knowledge hierarchy which highlights students; subject status and can arouse students' learning interest and combine to form more characteristic and diversified learning materials for students. The required course Systematic Anatomy is taken for example. The teaching material expounds and displays the components of each organ and physiological structure in detail. The teaching material involves detailed introduction and division of many organs and systems, such as digestive system, motor system, nervous system and endocrine system, with huge knowledge hierarchy and complex content. There are many knowledge points to be remembered. Just because of this, students may be easily weary of studying. To teach the course more smoothly and mobilize students' enthusiasm, it is required to arrange and integrate teaching contents again. The teacher may summarize the body structure that students have mastered and understood, and should focus on the internal structure that students are not familiars with. The teacher should break the set learning order of the teaching material and teach the course according to the organ structure order from the top to bottom, and lead students to observe and learn in the laboratory so as to combine theory and practice.

(2) To properly create rational situations to mobilize students' research interest and desire

In medical classroom teaching, it is very important to mobilize students' imagination and creativity, which is beneficial to arouse students' thirst for knowledge and learning interest. Properly creating rational learning situations is a very effective teaching method. Besides, it is also one of inevitable requirements of "autonomous-cooperative-exploratory" teaching mode for medical students based on the ability of evidence-based practice. Thus, in practical teaching process, teachers must consciously create learning situations which conform to classroom teaching content for medical students. For example, the teacher imports new course content with multimedia teaching equipment, then combines practice to guide students for thinking and finally encourages students to demonstrate and independently explain body structure by combining their own bodies.

(3) To encourage students to boldly propose questions

Classroom teaching is an open learning environment. It is required to give up the defects of traditional teaching mode and actively create the positive and cooperative learning atmosphere. In such learning environment, the teacher should actively guide students to propose questions boldly, think and explore. If every student in a class has no any doubt and question about the knowledge, these students do not carefully think and analyze at all. Therefore, the teacher should consciously encourage medical students to boldly put forward questions, actively explore and analyze the knowledge points they cannot understand, actively consult teachers and students and express their own views so as to develop the ability of independent study.

(4) To implement the diversified evaluation strategy and conduct all-round and systematic evaluation of students

The diversified evaluation strategy is one of essential requirements of "autonomous-cooperative-exploratory" teaching mode for medical students based on the ability of evidence-based practice. So, the teacher should make qualitative and quantitative personal evaluation of students' knowledge, ability, process, method, emotional attitude and values in classroom teaching. Moreover, comprehensive evaluation and examination of students' cooperation, medical experimental design and practical exploration should be conducted. The evaluation forms may include verbal evaluation, written evaluation or diagram. In one word, the ultimate aim is to enhance students' self-assessment and independent learning ability.

\subsection{Special implementation steps of "autonomous-cooperative-exploratory" teaching mode for medical students based on the ability of evidence-based practice}

Special implementation steps of "autonomous-cooperative-exploratory" teaching mode for medical students based on the ability of evidence-based practice include the following: to create classroom learning situation, to propose questions, to organize teaching activities for exploration, to draw conclusions and to give evaluative feedback. The following design may be conducted by combining the specific contents of Anthropotomy.

To create basic learning situation, boldly propose questions and confirm exploration direction of 
classroom teaching: PPT may be used to display the structures and physiological components of each organ. Or, flash animation may be applied to make human organs and systems "active", and to simulate their state in the body so as to attract students' learning interest and enthusiasm.

To cultivate students' autonomous learning ability and lay the foundation for inquiry-based learning: through independent study, students should have a basic understanding of the concept of anthropotomy and basic structure. The teacher should guide students to think the functions of these organs in the body.

To arrange and organize a series of exploration activities: 1) Exploration I: arrange student to complete experiment demonstration. The teacher should observe students' operation normativity and rationality in real time. Students should gain the method to learn anthropotomy by combining the experiment. 2) Exploration II: design detailed experiment al scheme to explore working state and functions of each organize and system.

Efficient display: students are classified into groups, and the group representative is selected to set forth the working process of each organ and system and motion state of various organs when they are suffering damages through PPT.

Evaluative feedback: under the leadership of the teacher, students' experimental scheme is comprehensively assessed so as to find out the most excellent experimental scheme. Besides, students comprehensive performance and practical operation ability including language expression ability should be evaluated so as to improve the medical thinking level, and autonomous, cooperative and exploratory learning ability.

\section{Conclusions}

In conclusion, "autonomous-cooperative-exploratory” teaching mode for medical students based on the ability of evidence-based practice organically integrates three kinds of learning modes: autonomous learning, cooperative learning and exploratory learning. This paper explores diversified learning methods which can give full play to medical students' subjectivity to help them establish independent study awareness and critical thinking ability. Such mode not just contributes to improving medical teaching method, but also can help medical students change their learning method. In one word, "autonomous-cooperative-exploratory" teaching mode for medical students based on the ability of evidence-based practice overcomes defects of traditional teaching mode, stresses the evaluation of learning process, learning interest and learning result, highlights the dominant position of medical students in the teaching activity and improves medical teaching quality. Hence, it has enlightenment and reference function in medical education.

\section{Acknowledgements}

This research was financially supported by The "Autonomous-Cooperative-Exploratory" Teaching Mode for Medical Students Based on Ability of Evidence-based Practice, "12th Five-year Plan” Youth Special Topic of Education and Science in Heilongjiang Province (GJD1215054).

\section{References}

[1] Zhong Zhaoming, Meng Tinging, Zheng Minghui, Chen Jianting, A Survey on Influencing Factors on Evidence-based Practice Competency of Medical Interns, Continuing Medical Education, 2013-03-15.

[2] Fan Bangxiong, Application of Evidence-based Medicine in Clinical Medication Intervention, Chinese Journal of Hospital Pharmacy, 2016-11-01.

[3] Hu Yan, Zhou Yingfeng, Xing Weijie, Enhancing capacity of evidence-based nursing in students in master of nursing specialist programs: reflections from teaching and learning, Chinese Journal of Nursing Education, 2015-10-20. 
[4] Han Chunmei, On "Autonomous-Cooperative-Exploratory" Experimental Teaching Mode, China Education Innovation Herald, 2013-12-21.

[5] Wang Yali, Li Zhongjun, on “Autonomous-Cooperative-Exploratory” Learning Mode, Market Modernization, 2010-06-10. 